\title{
The Effects of Teaching Supported by Self-Regulated Learning on Students' Learning and Studying Responsibility
}

\author{
Eker Cevat ${ }^{1}$, Eşref Akkaş² \\ ${ }^{1}$ Assoc. Prof. Dr. Ereğli Faculty of Education, Zonguldak Bülent Ecevit University, Zonguldak, Turkey \\ ${ }^{2}$ Dr, Ministry of Education, Turkey \\ Correspondence: Eker Cevat, Ereğli Faculty of Education, Zonguldak Bülent Ecevit University, Zonguldak, Turkey.
}

Received: September 5, 2019

Accepted: October 15, $2019 \quad$ Online Published: October 21, 2019

doi:10.11114/jets.v7i10S.4576

URL: https://doi.org/10.11114/jets.v7i10S.4576

\begin{abstract}
The purpose of this study is to determine the effects of teaching supported by self-regulated learning on students' learning and studying responsibility. This research was carried out through "pre-test-post-test control group model". The sample of the study consisted a total of 52 fifth grade students studying in two different classrooms of an urban primary school located in the West Black Sea Region in Turkey in the 2018-2019 academic year. This study was conducted for 4 weeks and the unit of "Culture and Heritage" in social studies lesson was covered. The learning and studying responsibility scale was used to collect the data. In the analysis of data, pre-test - post-test scores were compared by using t-test for dependent groups. In addition, in order to explain the power of relation, effect size (Cohens' d) values were calculated. The result of the study shows that teaching supported by self-regulated learning is effective and beneficial in students' learning and studying responsibility levels in favour of experimental group. This result demonstrated that teaching supported by self-regulated learning had positive effects on students' learning and studying responsibility.
\end{abstract}

Keywords: self-regulated learning, learning and study responsibilities, social studies

\section{Introduction}

Modern world in which information is rapidly renewed, one of the most important goals of education is to provide learning and studying responsibility for students. Students must have responsibility for their learning in order to become a lifelong learner (Devlin, 2002, 126). According to Popkin (1987), responsibility is to make choices and accept the outcomes and effects of these elections. While Lickona (1991) defines the responsibility as the active side of morality, according to the Turkish Language society (2018), responsibility is defined as the one assumes own behavior or the consequences of any event within own jurisdiction.

Learning responsibility is important because it base for learning other responsibilities and it has an effect on permanent learning (Günzenhauser, 2003; Meyer, 2005). One who has responsibility for learning always effort to learn (Bacon, 1993, 207). According to Barr and Tagg $(1995,699)$, when one takes responsibility, one sets goals and then acts to achieve them by modifying one's behavior. Participation in activities by taking learning responsibility is an important factor in providing permanent learning and positively improving the sense of responsibility (Başbay, 2008, 5).

Developing the students' responsibility of learning and studying can be seen as a means to be more successful in their education life. According to Allan (2006), students' responsibilities for learning are considered in six categories. These categories follow:

Orientation towards school and learning helps students to enhance their knowledge about learning environment in school.

Active participation in learning activities includes active participation of students' in teaching and learning process.

Autonomy and control of learning includes controlling their own learning and evolution of themselves as learners.

Initiative includes that the students arrange their own learning by taking responsibility.

Management of learning resources includes that students find the necessary information or resources to support learning. 
Cooperation and control of classroom behavior includes the management of students' behaviors in the learning environment and what they do when the students study as a group.

The learning responsibility begins from at the age of 5-6 years, increases at 7-8 years and begins to settle in later ages very well (Yıldırım \& Yıldırım, 1997). For this reason, it is primarily task of schools and teachers to gain students the responsibility of learning professionally. The attitude of the teacher is a decisive factor of the students to act responsibly (Yontar, 2007). During the classroom activities, teachers' support for the students in the face of difficulties becomes effective in developing the sense of responsibility (Carpenter \& Pease, 2013).

According to Bacon (1993), the responsible students give of their best to learn and have an attitude required to remove the obstacles for learning. As a sign of the students' responsibility to learn; "wanting to learn as much as possible", "tries to do best work whenever possible", "believing that school achievement is important for future success", "prefers class work/tasks to be challenging" are seen as attitude and behaviors (Allan, 2006).

The responsibility for learning and studying has a fundamental role in the development of a student community that supports learning. To educate students who take responsibility for their own learning is one of the most important tasks of all teachers (Carpenter \& Pease, 2013). Therefore, one of the most effective ways to develop a sense of responsibility is self-regulated learning. Self-regulated learning that emerges from the study of the educators who have researched the factors of the failures of low success students has become a very important concept in the area of education in recent years. While Bandura (1991) describes self-regulated learning as internal mechanisms that enable the development of individual's thoughts and emotions and motivating them to develop their identities, Pintrich (2005) defines self-regulated learning as an active, constructive process whereby learners set goals for their learning and then attempt to monitor, regulate, and control their cognition, motivation, and behavior, guided and constrained by their goals and the contextual features in the environment. Zimmerman, Bonner \& Kovach (1996) present self-regulated learning as a cyclical process consisting of four interrelated stages.

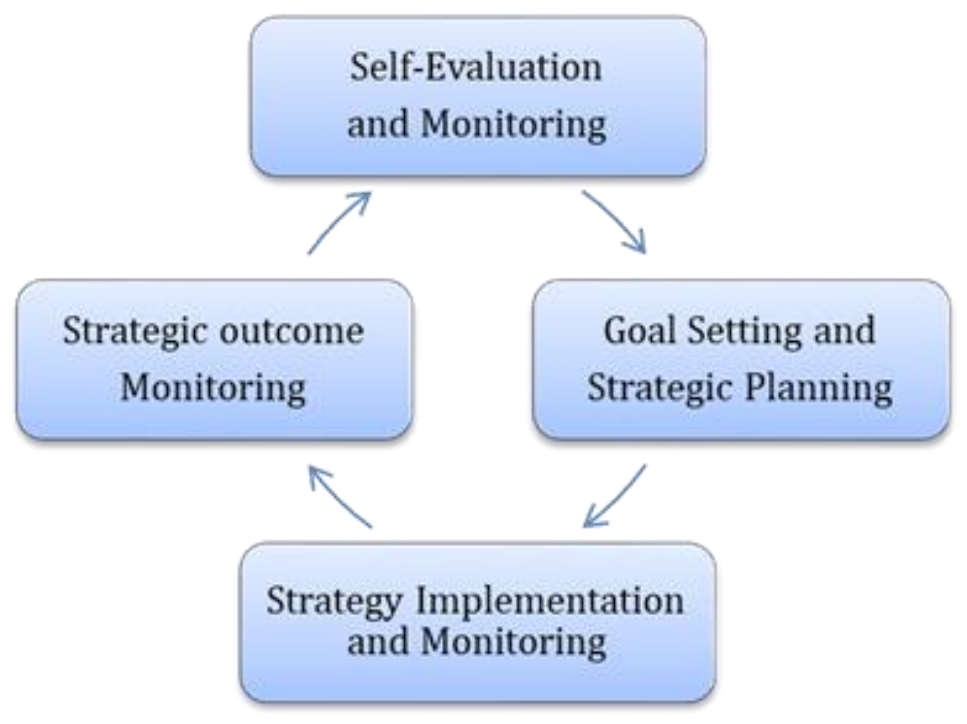

Figure 1. A Cyclic Model Of Self-Regulated Learning (Zimmerman, Bonner \& Kovach, 1996)

As seen in Figure 1, there are four interrelated processes in self-regulated learning. These processes;

Self-Evaluation and Monitoring: In this process, students judge their personal effectiveness from observations and recordings of prior performance.

Goal Setting and Strategic Planning: In this process, students set specific learning goals, analyze the learning task and plan or refine the strategy to attain the goal.

Strategy Implementation Monitoring: In this process, students try to execute a strategy in structured contexts and to monitor their accuracy in implementing it.

Strategic-outcome Monitoring: In this process, students focus their attention on links between learning outcomes and strategic processes to determine effectiveness. The most important point in this process is that learners indicate self-regulated learning by using the strategy appropriate to the goals of the student and by constantly self-monitor learning outcomes. 
Self-regulated learning strategies can be learned like other strategies (Zimmerman, 2000). The effective using of self-regulated learning strategies depends on students' ability to acquire and use these strategies correctly.

Cockelbergh (2006) states that the most important thing that needs to be done in relation to the responsibility education of the students is to give them responsibility and motivate them about their responsibilities. Students' knowing how they learn and teachers' organizing the appropriate learning-teaching activities for the different learner students are very important to reach the goals of education and to gain the responsibility of learning and working. For this purpose, the teacher should give an opportunity the students to determine their goals and evaluate their development. In addition, the teacher should give corrective feedback by looking at the students' practices. Students should be encouraged to gain learning and studying responsibility with more practice. It is thought that the learning and studying responsibility has an important role in the success in education. Therefore, this study is important to contribute the studies related to the students' responsibility of learning and working.

The purpose of this study is to determine the effects of teaching supported by self-regulated learning on students' learning and studying responsibility. For this purpose, it was tried to find answers for the following sub-problems.

1. Is there any significant difference between mean score of pre-test and post-test of the experimental group students' learning and studying responsibility in favour of post-test?

2. Is there any significant difference between mean score of pre-test and post-test of the control group students' learning and studying responsibility in favour of post-test?

3. Is there any significant difference between the experimental and control group students' learning and studying responsibility post-test mean scores in favour of experimental group?

\section{Method}

\subsection{Research Design}

This research was carried out according to "pre-test-post-test control group model". There were two groups formed by randomly assigning in pre-test, post-test control group model. Thus, an experimental and a control group were formed in this study. In both groups, measurements were made pre and after the experiment. Pre-tests which took place in the design and were applied to before practices help us to determine the level of similarity of the groups before experiment and last-tests help us interpretation of results (Cohen, Manion and Morrison, 2007). The experimental design used in this study was shown in Table 1.

Table 1. Experimental design of the study

\begin{tabular}{lccc}
\hline Groups & Pre-tests & Experimental Procedure & Post-test \\
\hline $\begin{array}{l}\text { Experimental } \\
\text { group }\end{array}$ & Scale of LSR & $\begin{array}{c}\text { Teaching activities by using self regulated } \\
\text { learning model }\end{array}$ & Scale of LSR \\
\hline \multirow{3}{*}{ Control Group } & $(30.11 .2018)$ & $(04.12 .2018 / 26.12 .2018)$ & $(28.12 .2018)$ \\
& Scale of LSR & Traditional method & Scale of LSR \\
& & $\begin{array}{c}\text { (Insruction activities based on high school } \\
\text { curriculum, teacher's book, approaches) }\end{array}$ & \\
& & &
\end{tabular}

LSR: Learning and studying responsibility

\subsection{Study Group}

This study covered a period of 4 weeks and the unit of "Culture and Heritage" in social studies lesson. The sample of the study consisted a total of 52 students at 5 th grade who studied in two different classroom of a primary school in the city which was medium sized in the West Black Sea Region in Turkey in 2018-2019 academic year. The distribution of students in the sample group was given in Table 2.

Table 2. Distribution of students located in the experimental and control group

\begin{tabular}{lllllll}
\hline \multirow{2}{*}{ Groups } & \multicolumn{2}{l}{ Female } & Male & \multicolumn{3}{l}{ Total } \\
\cline { 2 - 7 } & $\mathrm{N}$ & $\%$ & $\mathrm{~N}$ & $\%$ & $\mathrm{~N}$ & $\%$ \\
\hline Experimental group & 11 & 42.30 & 15 & 57.69 & 26 & 50 \\
Control group & 12 & 46.15 & 14 & 53.84 & 26 & 50 \\
Total & 23 & 44.23 & 29 & 55.76 & 52 & 100 \\
\hline
\end{tabular}


When Table 2 was examined, it was seen that there were 11 girls in the experimental group, 12 girls in the control group, 12 female students and 14 male students.

\subsection{Equalizing the Groups}

Except for the independent variable, it was found necessary to equalize the experimental subjects included in the study in terms of other variables. Because the independent variables in the research were required to be controlled in the experimental and control groups. The purpose of the variable control is to increase the internal validity and to ensure that the result obtained by the research is solely based on the independent variable tested. In the equalization process, experimental subjects with similar characteristics were included in the experimental and control groups. Thus, other variables that could affect experimental and control groups were tried to be controlled.

For this purpose;

1. From the data obtained from the pre-test scores of the learning and studying responsibility scale,

2. The opinion of social studies teachers were used.

The comparison of the students' learning and studying responsibility scale scores pre-test results of experimental and control groups: The students' learning and studying responsibility scale pre-test results which are used to balance the groups taking part in the study are given in Table 3.

Table 3. The comparison of the students' learning and studying responsibility scale scores pre-test results of experimental and control groups

\begin{tabular}{lllllll}
\hline Groups & $\mathrm{N}$ & $\bar{X}$ & $\mathrm{SD}$ & $\mathrm{sd}$ & $\mathrm{t}$ & $\mathrm{p}$ \\
\hline Experimental group & 26 & 30.12 & 8.17 & 50 & .52 & .68 \\
Control group & 26 & 33.46 & 8.22 & & &
\end{tabular}

$\mathrm{P}<.05$

When Table 3 is analyzed, the experimental group students' learning and studying responsibility scale pre-test mean score before the implementation is determined as ( $X=30.12, \mathrm{Ss}=8.17$ ) and the control group students' learning and studying responsibility scale pre-test mean score is determined as $(X=33.46, \mathrm{SD}=8.22)$. Whether there was a significant difference between the pre-test mean scores of the students in the experimental and control groups was calculated by using the t-test technique and with $[\mathrm{t}(50)=.52 ; \mathrm{P}<0.68]$ the difference was not statistically significant. In this case, it can be said that the experimental group students and control group students are in similar characteristics in terms of learning and studying responsibility at the beginning.

\subsection{Application Process}

This study was carried out in a way that it will cover a period of 4 weeks in the first semester of the $2018-2019$ academic years. 52 students studying in the 5th grade were participated into the study. The practicing study was applied to the experimental group for in a way that it would last for 3 hours. The research was carried out in three stages: preparation, implementation, data collection and evaluation.

\subsection{Data Collecting Tools}

The scale of learning and studying responsibility: In this study, learning and studying responsibility scale developed by Semerci and Pamuk (2012) was used. The scale was developed by applying 328 students at 4 th grade and 301 students at 5th grade who study in Elazı $\breve{g}$ in 2011-2012 academic year. The analysis of the research data was carried out by means of descriptive factor analysis. There were 16 positive and 2 negative substances in the scale which make totally 18 items. The items in the scale indicated the level of the students' learning and studying responsibility. The scale draft was structured as a five point Likert type scale. The responses aimed to determine the students' learning and studying responsibility were scored from negative (1) to positive (5) and from positive (5) to negative (1). The lowest and highest scores can be taken from the scale are 24 and 72 respectively.

\subsection{Analyzing of Data}

In this study, the obtained data were collected in two stages. Pre-test and post-test were applied to the experimental and control groups. In the analysis of data, mean $(X)$, standard deviation (SD), frequency (f), percentage (\%) t-test were used. In addition, for each relationship, to explain power of relation effect size (Cohens' d) values were calculated.

Effect size (Cohen's d) is a statistical value which is obtained from the sample, showing the level of results deviation from the expectations, calculated according to group mean difference (Cohen, 1994). However, statistical 
meaningfulness tests evaluate the possibility of obtaining the results from the sample by chance, effect size is an indication of the practical meaningfulness. While statistical meaningfulness is affected by the number of samples, effect size value helps to decide more accurately about obtained results by eliminating the consequences of the number of samples (Nickerson, 2000). The meanings which were given to effect size point values, can be seen in Table 4 .

Table 4. Cohen's D, the score intervals for the size of the effect

\begin{tabular}{|c|c|}
\hline \multicolumn{2}{|c|}{ The degree of the size of effect } \\
\hline Alternative & The limits of the intervals \\
\hline Uneffective & $0.0-0.2$ \\
\hline Partially effect & $0.2-0.5$ \\
\hline Medium effect & $0.5-0.8$ \\
\hline Big effect & $0.8+$ \\
\hline
\end{tabular}

The level which is .05 and trust interval which is $95 \%$ are used for commenting data.

\section{Findings}

In this section, experimental and control group students' pre-test-post-test and persistence test findings are given.

\subsection{Findings of First Sub-Problem}

First sub-problem of the study was questioned as following "Is there any significant difference between mean score of pre-test and post-test of the experimental group students' learning and studying responsibility in favour of post-test?" In accordance with this sub-problem, the findings about the experimental pre-process of academic achievement of the experimental and control group have been presented in table 5 .

Table 5. Comparison of the experimental group's students' mean score of pre-test and post-test about their learning and studying responsibility scale

\begin{tabular}{|c|c|c|c|c|c|c|c|}
\hline \multirow[t]{2}{*}{ Tests } & & \multicolumn{5}{|c|}{ The experimental group } & \multirow{2}{*}{$\begin{array}{l}\text { The size of effect } \\
\text { (Cohen's d) }\end{array}$} \\
\hline & $\mathrm{N}$ & $X$ & SD & $\mathrm{sd}$ & $\mathrm{t}$ & $\mathrm{p}$ & \\
\hline Pre-test & 26 & 30.12 & 6.17 & & & & 2.04 \\
\hline Post-test & 26 & 69.56 & 6.86 & 25 & 4.64 & 0.00 & \\
\hline
\end{tabular}

$\mathrm{P}<.05$

When Table 5 was examined, it was seen that experimental group students' mean score of pre-test of learning and studying responsibility scale is $(X=30.12)$ and its standard deviation is $(\mathrm{SD}=6.17)$, mean score of post-test is ( $X$ $=69.56)$ and its standard deviation is $(\mathrm{SD}=6.86)$. The difference between pre-test and post-test was in favor of the post-test. Whether the difference between the scores of pre-test and post-test was meaningful or not, was interpreted with ' $t$ test', and also a meaningful difference was found at the resulting $(\mathrm{t}=4.14)$ value and the level of $(\mathrm{P}<0.00)$. The effect size of the difference between pre-test and post-test scores of the experimental group was calculated as (d:2.04). It is seen that the experimental process has a major effect on learning and studying responsibility levels of experimental group students.

\subsection{Findings of Second Sub-Problem}

The second sub-problem of the study was questioned as following "Is there any significant difference between mean score of pre-test and post-test of the control group students' learning and studying responsibility in favour of post-test?". In accordance with this sub-problem, the findings related with the academic successes before the experimental process of the students in the experimental group are given in Table 6 .

Table 6. Comparison of learning and studying responsibility scale pre-test and post-test means score of the control group students

\begin{tabular}{cccccccc}
\hline Tests & \multicolumn{9}{c}{ The Control Group } & & $\begin{array}{c}\text { The size of effect } \\
\text { (Cohen's d) }\end{array}$ \\
\cline { 2 - 6 } & $\mathrm{N}$ & $\bar{X}$ & $\mathrm{SD}$ & $\mathrm{sd}$ & $\mathrm{t}$ & $\mathrm{p}$ & \multirow{2}{*}{0.62} \\
\hline Pre-test & 26 & 33.46 & 6.42 & & & \\
\hline Post-test & 26 & 51.86 & 6.94 & 25 & 3.81 & 0.02 \\
\hline 05 & & & & & &
\end{tabular}


When Table 6 was examined, it was seen that control group students' mean score of pre-test of learning and studying responsibility scale is ( $X=33.46)$ and its standard deviation is $(\mathrm{SD}=6.42)$, mean score of post-test is $(X=51.86)$ and its standard deviation is $(\mathrm{SD}=6.94)$. The difference between pre-test and post-test is in favor of the post-test. Whether the difference between the scores of pre-test and post-test is meaningful or not, was interpreted with ' $t$ test', and also a meaningful difference was found at the resulting $(\mathrm{t}=3.81)$ value and the level of $(\mathrm{P}<0.02)$. The effect size of the difference between pre-test and post-test scores of the experimental group was calculated as (d: 0.62). As a result, it can be said that courses processed as indicated in the program, have reasonable effects on the control group students' learning and studying responsibility levels.

\subsection{Findings of Third Sub-Problem}

The third sub-problem of the study was questioned as following "Is there any significant difference between the experimental and control group students' learning and studying responsibility post-test mean scores in favour of experimental group?". In accordance with this sub-problem, the findings related with the academic successes before the experimental process of the students in the control group are given in Table 7.

Table 7. Comparison of the post-test scores made to evaluate the learning and studying responsibility levels of the experimental group students and the control group students

Groups

\begin{tabular}{|c|c|c|c|c|c|c|}
\hline & $\mathrm{N}$ & $X$ & SD & $\mathrm{sd}$ & $\mathrm{t}$ & $\mathrm{p}$ \\
\hline Experiment & 26 & 69.56 & 6.86 & & & \\
\hline Control & 26 & 51.86 & 6.94 & 50 & 3.18 & 0.00 \\
\hline
\end{tabular}

The size of effect

(Cohen's d)

$\mathrm{P}<.05$

When Table 7 was examined, it was seen that experimental group students' mean score of post-test of learning and studying responsibility scale is ( $X=69.56$ ) and its standard deviation is ( $\mathrm{SD}=6.86$ ), control group students' mean score of post-test is $(X=51.86)$ and its standard deviation is $(\mathrm{SD}=6.94)$. The difference was in favor of the experimental group. Whether the difference between the scores of post-test was meaningful or not, was interpreted with t-test, and a meaningful difference was found at the resulting $(\mathrm{t}=3.18)$ value and the level of $(\mathrm{P}<0.00)$. The effect size of the difference between pre-test and post-test scores of the experimental group was calculated as (d:0.84). It was seen that the courses supported by self-regulated learning are effective on students' learning and studying responsibility level.

\section{Discussion}

\section{According to findings, the following conclusions were obtained:}

In this study which was researched the effect of self-regulated learning in Social Studies topics on students' learning and studying responsibility level, it was seen there were not statistically significant difference between the scores of the academic achievement pre-test of the experimental and control group. Accordingly, it was said that experimental and control groups were equivalent prior to application. When it was examined the students' academic achievement last-test scores, it was found that there have been significant increases in both the experimental and the control group. When the students' scale scores in the experimental group which teaching supported by self-regulated learning and the students' scale scores in the control group which teaching was done without supported by self-regulated learning were compared, it was found that academic achievement scores of students in the experimental group are higher. These results recommend that the teaching supported by self-regulated learning is more effective the teaching based on traditional methods.

According to these results, it can be said that self-regulated teaching is effective and beneficial in increasing students' learning and studying responsibilities. When we consider that self-regulated learning allows the student to regulate or direct their learning process (Phakiti, 2000), students who using these strategies in their studies understand their own deficiencies, make their own goals and plans and direct their own learning. Thus, it is thought that this strategies cause to appear such a difference.

In recent years, it was observed that researches in close relation with the responsibility education (Bacon, 1993; Allan, 2006; Clouder, 2009; Stockdale \& Brockett, 2010; Devlin, 2002; Carpenter \& Pease, 2013; Yeşil, 2014; Çatalbaş \& Semerci, 2016). It was seen that Çatalbaş \& Semerci (2016) made a research which supports the results of this study. Researchers aimed to determine the effect of self-regulated learning model based activities prepared for social studies lesson on student learning and studying responsibilities. The research results showed that self-regulated learning model aided activities had a positive impact on learning and studying responsibilities of the students. Yeşil (2014), aimed to examine the responsibility education strategies which are applied by primary education teachers in process of education. 
At the end of the research, it was determined that (1) teachers used informative responsibility education strategy more than applied responsibility education; (2) there were significant differences among the strategy applying level of teachers according to their education level, gender and level of seniority; (3) there were significant and positive relationship between seniority and responsibility education strategy which was applied.

Factors expressed to be effective in the awareness of learning and studying responsibility are accepted to be features such as self-regulation skills, motivation, self-fulfillment desire, individual ideals, self-esteem (Brecke \& Jensen, 2007; Ellinger, 2004). For school success, self-regulation, cooperation and academic skills are the factors that help students. While students who have self-regulated learning skills learn something, they can fulfill their own learning responsibilities about their work by controlling their feelings and thoughts (Zimmerman \& Schunk, 1989). In addition, when students have the responsibility of learning and studying, they understand the contents more deeply and learn the skills that will serve them well in various studies. Educators are required to support students in order to acquire the necessary skills in areas of self-regulation, cooperation and academic success which are the basis for deeply learning, success and personal development in school and life.

In the light of the results of the study, the following recommendations can be made:

For the reason that practices supported by self-regulated learning have a positive effect on the students' responsibility of learning and studying, self-regulated learning should be included frequently in the courses.

By preparing activities supported by self-regulation learning for different courses, students should be provided to acquire self-regulation skills and the effects of these skills on learning and studying responsibility should be examined.

\section{References}

Allan, G. M. (2006). Responsibility for learning: students' understandings and their self-reported learning attitudes and behaviours. Master Thesis. Queensland University of Technology, Faculty of Education, Centre for Learning Innovation Brisbane, Queensland.

Bacon, C. S. (1993). Student responsibility for learning. Adolescence, 28(109), 199-212.

Bandura, A. (1993). Perceived self-efficacy in cognitive development and functioning. Educational Psychologist, 28(2), 117-148. https://doi.org/10.1207/s15326985ep2802_3

Barr, B. R., \& Tagg, J. (1995). From teaching to learning: A new paradigm for undergraduate. https://doi.org/10.1080/00091383.1995.10544672

Başbay, A. (2008). Relationship between learners' individual learning tasks and their mental skills and decision making pace. Education and Science, 33, 3-17.

Brecke, R., \& Jensen, J. (2007). Cooperative learning, responsibility, ambiguity, controversy and support in motivating students. InSight: A Collection of Faculty Scholarship, 2, 57-63.

Carpenter, P. J., \& Pease, S. J. (2013). Preparing Students to Take Responsibility for Learning: The Role of Non-Curricular Learning Strategies, Journal of Curriculum and Instruction (JoCI), 7(2), 38-55. https://doi.org/10.3776/joci.2013.v7n2p38-55

Clouder, L. (2009). 'Being responsible': students' perspectives on trust, risk and work-based learning. Teaching in Higher Education, 14(3), 289-301. https://doi.org/10.1080/13562510902898858

Coeckelbergh, M. (2006). Regulation or responsibility? Autonomy, moral imagination, and engineering. Science, Technology, \& Human Values, 31(3), 237-260. https://doi.org/10.1177/0162243905285839

Cohen, J. (1994). The earth is round ( $\mathrm{p}$ <.05). American Psychologist, 49, 997-1003.

Cohen, L, Manion, L., \& Morrison, K. (2007). Research Methods in Education (6th edition). London, Routledge Falmer.

Çatalbaş, A., \& Semerci, Ç. (2016). The effect of self regulated learning model based activities prepared for social studies lesson on student responsibilities of learning and study. Journal of Abant İzet Baysal University Faculty of Education, 16(2), 399-412. https://doi.org/10.17240/aibuefd.2016.16.2-5000194934

Devlin, M. (2002). Taking responsibility for learning isn't everything: A case for developing tertiary students' conceptions of learning. Teaching in Higher Education, 7(2), 125-138. https://doi.org/10.1080/13562510220124231

Ellinger, A. D. (2004). The concept of self-directed learning and its implications for human resource development, Advances in Developing Human Resources, 6(2), 158-177. https://doi.org/10.1177/1523422304263327 
Gunzenhauser, M. G. (2003). High-stakes testing and the default philosophy of education. Theory into Practice, 42(1), 51-58. https://doi.org/10.1207/s15430421tip4201_7

Lewis, R., Romi, S., \& Roache, J. (2012). Excluding students from classroom: Teacher techniques that promote student responsibility, Teaching and Teacher Education, 28(6), 870-878. https://doi.org/10.1016/j.tate.2012.03.009

Lickona T. (1991). Educating for Character: How Our Schools Can Respect and Responsibility. New York: Bantam Books.

Meyer, L. (2005). The complete curriculum: Ensuring a place for the arts in America's schools. Art Education Policy Review, 106(3), 35-39. https://doi.org/10.3200/AEPR.106.6.3-18

Nickerson, R. S. (2000). Null hypothesis significance testing: A review of an old and continuing controversy. Psychological Methods, 5, 241-301.

Phakiti, A. (2003). A closer at gender and strategy use in L2 reading. Language Learning, 53(4), 649-703.

Pintrich, P. R. (2005). The role of goal orientation in self-regulated learning. In M. Boekaerts, P. R. Pintrich and M. Zeidner (Eds.), Handbook of self-regulation (p. 451-502). San Diego, CA: Academic Press. https://doi.org/10.1016/B978-012109890-2/50043-3

Popkin, M. (1987). Active Parenting: Teaching, Cooperation and Responsibility. San Fransisco: Harper \& Row Publishers.

Semerci, Ç., \& Pamuk, M. (2012). Developing the scale of learning and work responsibility: validity and reliability analysis. Measurement and Evaluation in Education and Psychology III. National Congress. 19-21 September 2012. Abant İzzet Baysal University, Bolu.

Stockdale, S. L., \& Brockett, R. G. (2010). Development of the PROSDLS: A measure of self-direction in learning based on the personal responsibility orientation model, Adult Education Quarterly, 200(10), 1-20.

Turkish Language Society (2018). Great Turkish Dictionary, Access date:01.12.2018, http://www.tdk.gov.tr/index.php?option=com_bts\&arama=kelime\&guid=TDK.GTS.5c4f54fa9342e4.82961947,

Yeşil, R. (2014). Examination of the responsibility education strategies of primary school teachers, Hacettepe University Journal of Education, 29(2), 282-294.

Yıldırım, N., \& Yıldırım, K. (1997). Sociology of education, Edirne Trakya University, Faculty of Education, Edirne: Desktop Publishing.

Yontar, A. (2007). Examining the opinions of 5th grade elementary school teachers and students about criminal practices in responsibility education. (Unpublished Master Thesis), Adana Çukurova University / Institute of Social Sciences.

Zimmerman, B. J. (2000). Theories of self-regulated learning and academic achievement: An overview and analysis. In B. J. Zimmerman \& D. H. Schunk (Eds), Self-regulated learning and academic achievement: Theoretical perspectives (pp. 1-38). Mahwah, NJ: Lawrence Erlbaum.

Zimmerman, B. J., \& Schunk, D. H. (1989). Self-regulated learning and academic achievement. New York: Academic Press.

Zimmerman, B. J., Bonner S., \& Kovach, R. (1996). Developing self-regulated learners, beyond achievement to self-efficacy. Washington: American Psychological Association. https://doi.org/10.1037/10213-000

\section{Copyrights}

Copyright for this article is retained by the author(s), with first publication rights granted to the journal.

This is an open-access article distributed under the terms and conditions of the Creative Commons Attribution license which permits unrestricted use, distribution, and reproduction in any medium, provided the original work is properly cited. 